\title{
O DESAFIO DA PRÁTICA PEDAGÓGICA COM ALUNOS COM DEFICIÊNCIAS: NARRATIVAS DE PROFESSORAS DA EDUCAÇÃO INFANTIL
}

FRANCISCA FRANCIELIS AZEVEDO MAFRA DE OLIVEIRA*

\section{RESUMO}

O presente texto procura refletir a prática pedagógica de três professoras de alunos com deficiências da educação infantil do município de Tabatinga, Amazonas. É parte de um recorte das experiências vivenciadas ao longo de quatro anos como professora de Atendimento Educacional Especializado, que, de forma direta lidava com as professoras que tinham em sua sala de aula alunos com deficiências. Das inúmeras professoras envolvidas nesse contexto durantes esse anos optamos por selecionar apenas as narrativas de três, sendo a primeira com 15 anos de experiência, a segunda com dez anos de experiência e a terceira com 5 anos de experiência de prática pedagógica na educação infantil, por entender que a análise dessas narrativas tornam-se de certa forma muito ampla pelo número de informações que cada relato trás em suas entre linhas. Optamos por abordar temas que envolvem diretamente a prática pedagógica das professoras. $\mathrm{O}$ eixo metodológico tem caráter qualitativo de cunho descritivo-analítico e foram utilizados dados obtidos por meio de narrativa

* Aluna do curso de Mestrado em Educação, da Universidade Metodista de São Paulo. Pedagoga, formada pela Universidade do Estado do Amazonas - UEA Pós-graduada em Educação Especial e Inclusiva, pela Faculdade Táhirih. Especialista em Atendimento Educacional Especializado-AEE e Salas de Recursos pela Universidade Candido Mendes. Especialista em Docência do Ensino Superior e Neuropsicopedagogia pela Universidade ÚNICA. Mestranda em Educação, pela Universidade Metodista de São Paulo - UMESP. Email- ffam-oliveira@hotmail.com 
em que as vivências da prática pedagógica em relação ao contexto da inclusão escolar são abordados. As narrativas das professoras têm indicado pistas para a compreensão sobre a maneira como os alunos com deficiência têm sido inclusos na escola e como essa "inclusão" tem produzido barreiras ou acesso ao processo de ensino e aprendizagem dos mesmos. Uma primeira reflexão crítica dessas narrativas tem indicado possibilidades para os professores reconsiderarem seus posicionamentos sobre a escolarização dos alunos, intensificando os saberes-fazeres docentes e as práticas pedagógicas, pois as narrativas, em muitas situações, fazem correlações entre a deficiência e a impossibilidade de a pessoa com algum tipo de limitação poder aprender, conjugando a diferença aos pressupostos da desigualdade e da exclusão social/escolar, dificultando dessa forma o acesso ao conhecimento sistematizado. Palavras-chave: Práticas Pedagógicas. Educação Infantil. Deficiências.

\begin{abstract}
This text seeks to reflect the pedagogical practice of three teachers of students with disabilities in the kindergarten of Tabatinga Amazonas. It is part of an excerpt of the experiences she lived over four years as a Specialized Educational Care teacher who directly dealt with the teachers who had students with disabilities in her classroom. Of the many teachers involved in this context during these years, we chose to select only the narratives of three, the first with 15 years of experience, the second with ten years of experience and the third with 5 years of experience of pedagogical practice in early childhood education. Since the analysis of these narratives becomes somewhat broad by the number of information that each narrative brings in its between lines, we chose to address themes that directly involve the teachers' pedagogical practice. The methodological axis has a qualitative character of descriptive-analytical nature and we used data obtained through narrative in which the ex-
\end{abstract}


periences of pedagogical practice in relation to the context of school inclusion are addressed. Teacher narratives have indicated clues to understanding how students with disabilities have been included in school and how this "inclusion" has produced barriers or access to their teaching and learning process. A first critical reflection of these narratives has indicated possibilities for teachers to reconsider their positions on students' schooling, intensifying teaching know-how and pedagogical practices, since narratives, in many situations, correlate the deficiency with the impossibility of teaching. A person with some kind of limitation can learn, combining the difference with the assumptions of inequality and social / school exclusion, thus hindering access to systematized knowledge.

Keywords: Pedagogical Practices, Early Childhood Education, Disabilities

\section{INTRODUÇÃO}

Considerando que os fundamentos da Educação Inclusiva baseiam-se numa concepção de educação de qualidade para todos e no respeito à diversidade dos educandos, é imprescindível uma participação mais qualificada dos educadores para o avanço desta importante tarefa educacional, para o atendimento das necessidades educativas de todos os alunos, com ou sem deficiências.

O presente texto trás uma reflexão quanto à prática pedagógica de três professoras com alunos com deficiências da educação infantil do município de Tabatinga, Amazonas. Este estudo é parte de um recorte das experiências vivenciadas ao longo de quatro anos como professora da sala de recursos, que, de forma direta, lidava com as professoras que tinham em sua sala de aula alunos com deficiências.

Das inúmeras professoras envolvidas nesse contexto durante esses anos, optamos por selecionar apenas as narrativas de três, sendo a primeira com quinze anos de experiência, a segunda com dez anos e terceira com cinco anos de prática na educação 
infantil, por entender que a análise dessas narrativas torna-se de certa forma muito ampla pelo número de informações que cada relato trás em suas entrelinhas. Optamos então por abordar temas específicos que envolvem diretamente a prática pedagógica das professoras.

No percurso metodológico utilizamos como abordagem a pesquisa narrativa, que na visão de Connelly e Clandinin (2011), identifica:

Os seres humanos são organismos contadores de histórias, organismos que individual e socialmente, vivem vidas relatadas. O estudo da narrativa, portanto, é o estudo da forma como nós, seres humanos experimentam o mundo. Dessa ideia geral se deriva a tese de que a educação é a construção e a reconstrução de histórias pessoais e sociais: tanto os professores como os alunos somos contadores de histórias e também personagens nas histórias dos demais e nas suas próprias.

Dessa forma, fizemos a observação do cotidiano escolar da prática pedagógica dos professores durante os quatro anos que convivemos com elas, bem como realizamos entrevista para capturar as narrativas das professoras.

O eixo metodológico tem caráter qualitativo de cunho descritivo-analítico e foram utilizados dados obtidos por meio de narrativas da prática pedagógica em relação ao contexto da inclusão: Lei da Inclusão, formação inicial e continuada dos professores da Educação Infantil, processo de ensino e aprendizagem dos alunos com deficiência. De experiências vivenciadas durante alguns anos desenvolvendo a prática pedagógica como professora de educação especial e de troca de experiências com professoras que lidavam com alunos com deficiências em sua classe comum de ensino, pode-se dizer que muitos são os obstáculos no processo de inclusão - um dos quais é o 
modo como às pessoas se relacionam com a diferença e como significam a deficiência.

Em diversas situações, a deficiência é entendida por um conjunto de imagens que guiam sentimentos de desprezo, medo e hostilidade. Essa condição afeta as relações entre as pessoas, seja no campo intelectual, racional, relacional, emocional e/ ou no afetivo. Tal situação cria, assim, imagens e informações inadequadas, indisposições psíquicas ou afetivas em relação à pessoa que apresenta algum tipo de deficiência e necessidade especial de aprendizagem.

Percebemos que essa imagem constituída sobre a deficiência tem levado professores a produzir narrativas sobre os modos de ser/estar de estudantes apoiados pela Educação Especial que vivenciam processos de inclusão na escola de ensino regular. Com base nas demandas investigativas aqui expostas, cabe questionar: o que narram as professoras sobre o ensino e aprendizagem de alunos com deficiências da educação infantil na escola regular? Essas narrativas podem fundamentar momentos de reflexão sobre a importância da formação continuada dos professores?

Pretendemos com esta reflexão crítica sobre as narrativas das professoras despertar um olhar mais sensível da comunidade e quem sabe dos governantes para a necessidade de investimento na formação continuada dos profissionais da educação, pois, acreditamos que o conhecimento necessário para os professores que lidam com alunos com deficiências vai além daqueles adquiridos na primeira formação. E estes, sim, podem contribuir para a superação de práticas excludentes e para a ressignificação dos alunos com deficiência, favorecendo a aprendizagem e a inclusão dos mesmos na sociedade como um todo.

\section{LEI DA INCLUSÃO ESCOLAR}

O debate sobre a Educação Especial e Inclusiva no Brasil, em especial no aspecto de incluir a todos em instituições de ensino regulares, tem sido intenso nos últimos anos. Atualmente, 
o MEC vem fazendo um esforço para reformar a atual Política Nacional de Educação Especial na Perspectiva da Educação Inclusiva (PNEEPEI), que é de 2008. O texto proposto enfrenta forte oposição de alguns grupos de educadores que tratam do assunto, para os quais a nova redação voltaria a estimular a separação das pessoas com deficiência.

Mantoan (2006) considera que é importante que as escolas especiais compreendam que seu papel é o de complementar as ações da escola regular. Para a autora, as escolas especiais destinam-se a uma perspectiva de trabalho diferenciada, mas "[...] que garante e possibilita ao aluno com deficiência a aprendizagem desses conteúdos quando incluídos nas turmas comuns". (MANTOAN, 2006, p. 26).

Segundo a pesquisadora, falta às escolas especiais e às instituições para pessoas com deficiência a compreensão do papel formador da escola comum que jamais será exercido em um meio educacional segregado. A autora afirma ainda que faltalhes a consciência de que as escolas especiais se descaracterizam, perderam sua identidade, bem como os profissionais que nelas lecionam, particularmente os que são professores especializados.

No entanto, está previsto na Lei Brasileira da Inclusão em seu artigo 27 :

"A educação constitui direito da pessoa com deficiência, assegurados sistema educacional inclusivo em todos os níveis e aprendizado ao longo de toda a vida, de forma a alcançar o máximo desenvolvimento possível de seus talentos e habilidades físicas, sensoriais, intelectuais e sociais, segundo suas características, interesses e necessidades de aprendizagem". (Brasil, 2015)

A lei ainda prevê que é dever do Estado, da família, da comunidade escolar e da sociedade assegurar educação de qualidade à pessoa com deficiência, colocando-a a salvo de toda forma de violência, negligência e discriminação. 
Neste sentido, quando analisamos as narrativas das professoras sobre a inclusão desses alunos na escola, logo percebemos a aflição que elas transmitem ao dizer: (Professora 1) “... a lei da inclusão é muito bonita no papel, mas o difícil é ter que coloć-la em prática no dia a dia da sala de aula, sem ter o menor suporte pedagógico". (Depoimento concedido à pesquisadora, Tabatinga 20 setembro, 2019).

Neste sentido permito-me dizer que o processo de inclusão em escola regular vai além da simples inserção do aluno em sala de aula, e baseio-me em ABE (2009) quando diz que inclusão requer preparo estrutural e acessível da escola, bem como capacitação de professores e funcionários.

No convívio com professoras de uma escola municipal de Educação Infantil no município de Tabatinga-AM, observamos que embora elas procurem acolher os alunos com deficiências ou com necessidades educacionais especial, encontram dificuldades para atender as especificidades que apresentam quanto ao ritmo diferenciado na realização das atividades, formas de comunicação não usuais, comportamentos não esperados e inadaptação.

As professoras afirmam que o acesso à educação está legalmente assegurado, mas muito ainda precisa ser feito para que o ensino disponibilizado seja de qualidade. Elas destacam, dentre outros fatores, que o trabalho docente é dificultado pelo desconhecimento que os profissionais da educação têm sobre as características de desenvolvimento e aprendizagem dessas crianças com deficiências.

Professora 2: “... Não sabemos o que esses alunos têm, não temos conhecimento sobre todas as deficiências; somos apenas professoras e não especialistas em deficiências". (Depoimento concedido à pesquisadora, Tabatinga 20 setembro, 2019).

Uma das maiores queixas das professoras está relacionada ao fato de elas não saberem qual é de fato a deficiência de alguns alunos, pois a grande maioria dos alunos do público-alvo da educação especial da escola não possui laudo médico. 
Sabe eu penso que a mesma Lei que nos obriga a receber esses alunos deveria obrigar os governantes a garantir a eles todos os especialistas que eles precisam, como, neurologista, fonoaudiólogo, psicólogos, etc., pois eles querem que nós professores demos conta do trabalho que é de toda uma equipe, e isso realmente não e justo. (Professora 3, Depoimento concedido à pesquisadora, Tabatinga 20 setembro, 2019).

Neste sentido, podemos dizer que a preparação de educadores para atender alunos do público-alvo da educação especial necessita ser reconsiderada, com a intenção de lhes habilitar a trabalhar em ambientes diferentes e de assumir um papel importante no contexto educacional de qualidade. Portanto, se fazem necessários programas de formação continuada para preparação apropriada de todos os educadores, bem como a inserção de uma equipe multidisciplinar dentro de cada escola para dar suporte ao trabalho das mesmas.

\section{FORMAÇÃO INICIAL E CONTINUADA DOS PROFESSORES DA EDUCAÇÃO INFANTIL}

A formação do professor é um desafio na proposta da escola inclusiva, sendo uma atividade de suma importância, posto que a educação é para todos, mas a maioria dos professores não está preparada para atender estudantes do público-alvo da educação especial. Um dos maiores desafios que emergem da proposta de escola inclusiva é a formação do professor, que, para Fávero (2009), é justamente o de repensar e ressignificar a própria concepção de educador.

Diante deste contexto podemos destacar que, embora as três professoras selecionadas para compor esta pesquisa tenham formação em nível superior, percebemos que elas não se sentem preparadas para lidar com os alunos com deficiências. Elas atribuem a falta de conhecimento como uma das principais 
justificativas para o insucesso da inclusão escolar desses alunos.

Vale destacar que umas das professoras não é formada em Pedagogia, e sim em Letras, e mesmo assim assumiu a turma de Educação Infantil na expectativa de ser mais fácil o desenvolvimento do trabalho pedagógico, algo que fica bem evidente em sua fala.

Professora 1. "Eu sou graduada em Letras, mas na época que fizo concurso só era exigido ter nivel superior em qualquer licenciatura. Então, quando passei, optei pela Educação Infantil, achei que dava menos trabatho e era mais fácil ensinar as crianças". (Depoimento concedido à pesquisadora, Tabatinga 20 setembro, 2019).

As docentes também narram que a falta de formação continuada tem sido constante no meio pedagógico desde que entraram no magistério, não só em relação à inclusão escolar, como em diversas áreas da educação. Percebemos na fala das professoras que algumas até possuem especialização, mas que ainda assim não se sentem preparadas para lidar com situações de inclusão escolar.

Foi época em que para ser professora era necessário ter ensino superior; então foi implantado o curso Normal Superior, que capacitava para ser professor da Educação Infantil ao $5^{\circ}$ ano. Então eu cursei e me formei, mas já atuava como professora de Educação Infantil. Logo em seguida fiz uma especialização em Psicopedagogia, não deu pra aprender muito porque as aulas eram uma vez por mês e a gente queria mesmo era o certificado. (Professora 2, Depoimento concedido à pesquisadora, Tabatinga 20 setembro, 2019).

Dessa forma destacamos que são raras as exceções em relação ao desejo de fazer a diferença na vida do aluno com deficiência e que realmente exercer a profissão por gostar daquilo 
que faz e por acreditar que, sim, é possível, mesmo sem muito conhecimento fazer da melhor maneira o seu papel, fato bem evidente na narrativa seguinte.

Fiz Normal Superior e também Pedagogia na universidade pública. Sempre quis ser professora - minha mãe era e eu queria seguir os passos dela, pois tinha nela minha inspiração. Logo no primeiro ano tive alunos com deficiências e senti a necessidade de ter mais conhecimentos, então fiz especialização em Educação Especial e Inclusiva; sou de uma turma de 45 alunos formados, mas apenas 3 atuavam com alunos com deficiências. Mesmo que a secretaria não oferecesse formação eu sempre procurei ler e estudar bastante sobre a inclusão, as deficiências, as doenças raras que estão surgindo no mundo. Acredito que nós, professores, é que temos que procurar o conhecimento... ele não cai do céu e nem vem de graça, tudo na vida requer esforço... (Professora 3, Depoimento concedido à pesquisadora, Tabatinga 20 setembro, 2019).

Notamos ainda que a Educação Especial na perspectiva da inclusão se constitui a inserção de todos os alunos com deficiência no ensino regular, na tentativa de oportunizar espaços e tempos de aprendizagem a todos. Contudo, essa realidade apresenta-se como um desafio não só para a formação inicial de professores, como também para a formação continuada, uma vez que é preciso compreender a inclusão escolar não apenas como uma forma de incluir, mas, sim, de garantir a permanência desses alunos no ensino regular e, consequentemente, a sua aprendizagem satisfatória.

Nessa perspectiva, sem dúvida, a formação inicial e continuada dos professores apresenta-se como um desafio no que diz respeito à inclusão escolar, pois é preciso um movimento que ressignifique as práticas de formação numa perspectiva da reali- 
dade escolar e, principalmente, que encontre sentido potencializador para a aprendizagem do aluno incluso no ensino regular.

Bueno (1999) faz a defesa de que o sentido da vivência da Educação Especial, desde a formação inicial, poderia contribuir também para o ensino regular, uma vez que o professor teria a oportunidade de compreender as formas de atuação nesse espaço, bem como identificar as características de ser docente no espaço da inclusão escolar.

Esse perfil formativo, na visão do autor, poderá fazer como que o docente busque ainda na formação continuada ou em estudos parceria em relação aos conhecimentos e recursos a serem utilizados para auxiliar seus alunos.

Finalizando esse tópico de reflexão, cabe ressaltar que quando o professor encontra desde o início da sua graduação experiências teórico/práticas relacionadas à Educação Especial na perspectiva da inclusão, ele terá maior possibilidade de construção da docência nesse espaço de atuação pedagógica. É importante ressaltar ainda que é necessário que o professor busque conhecimento para que, assim, possa distinguir os problemas para apresentar melhor alternativa de assimilação. Neste viés a formação continuada é imprescindível para a dinamização do processo de ensino e aprendizagem.

\section{PROCESSO DE ENSINO E APRENDIZAGEM DOS ALUNOS COM DEFICIÊNCIA}

As narrativas das professoras sobre as primeiras impressões da realidade escolar após sua inserção na sala em que tinham alunos com deficiências, revelaram que se sentiram assustadas e que o desespero foi maior quando perceberam que não possuíam o conhecimento de todos os aspectos dos alunos e de suas deficiências. Isso fica bem evidente em suas falas:

Há quinze anos sou professora nesta escola, e esse é o primeiro ano que eu tenho aluno com deficiência na sala. 
O problema não é ele ser deficiente, é que eu não me sinto preparada para lidar com ele. "Além do mais tenho outros 24 alunos que necessitam de atenção e precisam aprender. (Professora1, Depoimento concedido à pesquisadora, Tabatinga 20 setembro, 2019).

Outros relatos das educadoras sobre suas vivências:

Sou a professora há dez anos; antes era muito raro a gente ver alunos com deficiências na escola, os poucos que havia começavam o ano, mas nunca terminavam. Geralmente adoeciam ou não se adaptavam. Alguns pais não tinham confiança em deixá-los na escola, queriam ficar juntos e como não podia, acabavam tirando-os da escola. (Professora 2, Depoimento concedido à pesquisadora, Tabatinga 20 setembro, 2019).

Sou professora há cinco anos. Quando comecei a trabalhar tinha acabado de concluir o curso de Pedagogia e muita vontade de ser professora, pois acreditava que eu podia fazer diferente as coisas que eu presenciei durante meu estágio. Mas fui surpreendida logo de cara com uma turma superlotada de 30 alunos de 5 anos de idade, sendo dois com deficiência. Um deles tinha Síndrome de Down e o outro era autista. Meus sonhos ficaram em segundo plano; o que eu tinha era uma dura realidade pela frente. (Professora 3, Depoimento concedido à pesquisadora, Tabatinga 20 setembro, 2019).

Para além da compreensão da formação e das dificuldades, é preciso que tenhamos dentro do próprio ambiente de trabalho a colaboração entre os docentes experientes e aqueles que estão começando a ensinar crianças com deficiências. As professoras afirmam a importância do auxílio da escola para seu desenvolvi- 
mento profissional, bem como chamam atenção para a necessidade de terem uma equipe multidisciplinar, tendo em vista que a maioria dos alunos com deficiências não dispõe de laudo médico para ajudar as docentes a adotar um direcionamento ao curso.

Com isso, em seus depoimentos, ao abordarem a respeito das intervenções pedagógicas realizadas por elas com os estudantes deficientes matriculados em sua classe, a maioria nunca propunha metodologias diferenciadas como forma de abranger todos os estudantes na mesma atividade, com vistas a propiciar a participação e inclusão. Ao contrário, planejavam sequências didáticas nivelando pelo conhecimento da maioria, e com isso acabam promovendo a exclusão.

Eles não aprendem mesmo, só estão na escola por conta dessa lei, pois não podemos negar matrícula. Pra ser sincera, se eu tivesse um filho assim eu não o deixaria ir pra escola, pois lá ele pode até ser maltratado e não vai poder se defender e nem poder avisar os pais do que está acontecendo. (Professora 1, Depoimento concedido à pesquisadora, Tabatinga 20 setembro, 2019).

Outros depoimentos:

Alguns alunos conseguem aprender pelo menos a conviver com outras crianças, mas dificilmente eles vão conseguir seguir o ritmo da turma. Já vi casos na escola de estarem na sala por estar, estão inseridos, mas não inclusos, pois não desenvolvem atividade nenhuma. Não vejo muito sentido em forçar essa aprendizagem; é desgastante tanto para o professor quanto para o aluno, que não tem muita noção do que esperam dele. Isso até frustra o professor, quando faz tanta coisa, se desgasta tanto e não vê resultado. (Professora 2, Depoimento concedido à pesquisadora, Tabatinga 20 setembro, 2019). 
Ao observarmos essas falas pudemos perceber que existe um comodismo nas professoras, pois a maioria delas não estimula nenhum potencial no aluno deficiente e justifica suas atitudes dizendo que eles não conseguem realizar as atividades propostas por serem deficientes. Elas, com muita frequência, dizem: "os alunos não falam, não simbolizam, não dão feedback ao professor; não acompanham a turma; não apresentam possibilidades de aprendizagem; não se locomovem. Acreditamos que esse termo poderia ser mudado talvez por "ainda não, estão em processo de ... e muitos outros menos excludentes e menos rotulado.

Acredito que se nós tivéssemos maior suporte pedagógico, quem sabe uma equipe multidisciplinar que nos ajudasse a entender melhor como cada aluno deficiente aprende e o que é mais significativo, para ele aprender, essa aprendizagem poderia ser melhor desenvolvida. Nossos conhecimentos pedagógicos são muito limitados como professores e, o pior, é que muitas vezes temos que desenvolver atividades de outras áreas como: psicólogo, fonoaudiólogo, fisioterapeuta como se fossemos super heróis. Pois quando entregam uma criança deficiente para a gente ensinar não querem nem saber como vai ser feito, é tipo assim 'cuida que o filho é teu'. Ouvi isso muitas vezes de colegas de escola e até do próprio apoio pedagógico, que não tinha o menor conhecimento na área de educação especial. Ela era formada em letras e nunca se preocupou em nos ajudar com aquelas crianças. Ao contrário, passou a "bola" pra professora da sala de recursos a quem sempre recorríamos quando estávamos sem saber o que fazer, ou quando precisávamos desenvolver uma atividade mais focada com aquela criança, mesmo sabendo que eles não iriam aprender. Sempre nos esforçávamos. (Professora 3, Depoimento concedido à pesquisadora, Tabatinga 20 setembro, 2019). 
Diante desses relatos podemos dizer que é imprescindível uma participação mais qualificada dos educadores para que haja o atendimento das necessidades educativas de todos os alunos, com ou sem deficiências. No entanto o que pudemos observar a partir deste estudo é que infelizmente, o despreparo dos professores figura entre os obstáculos mais citados para a educação inclusiva. Nesse sentido podemos dizer que é um grande desafio, fazer com que a inclusão ocorra, sem perdermos de vista que além das oportunidades, é preciso garantir o avanço na aprendizagem, bem como, no desenvolvimento integral do estudante.

\section{CONSIDERAÇÕES FINAIS}

O presente texto teve como foco principal refletir a prática pedagógica desenvolvida por professoras de alunos com deficiências matriculados na educação infantil de uma escola municipal, a partir de seus relatos. Esta temática se torna relevante uma vez que procura reconhecer a importância a e relevância da temática em discussão, levando o professor a refletir e discutir a importância das suas ações diante das diversidades encontradas nas escolas, visando um processo de ensino e aprendizagem de valorização e de respeito ao ser humano em suas origens social, cultural e econômicas a fim de garantir uma educação de qualidade para todos, além de aprendizagens efetivas e significativas.

A realização desta experiência permitiu analisar como as professoras vêm construindo sua carreira a partir dos relatos de suas experiências na Educação Especial. A partir dos dados observados tivemos a oportunidade de conhecer e descrever a trajetória de formação e constituição da docência e das suas práticas pedagógicas. Com isso, constatamos que os processos de ensino adotados pelas professoras ganham um sentido mais prático e não incorporam elementos importantes das recomendações da inclusão escolar. Esse dado é característico das fragilidades da 
formação inicial na falta de algumas disciplinas essenciais para a discussão teórico-metodológica da atuação nesse contexto.

As narrativas docentes explicitaram também a falta de efetivação de políticas públicas referentes à formação profissional e continuada das professoras de Educação Infantil e Especial, comprometendo, assim, as práticas educativas construídas com as crianças, pois acreditamos que se a professoras não possuem o conhecimento necessário, não terão condições de desenvolver uma boa prática pedagógica.

Entendemos a partir destas reflexões que é imprescindível que os educadores em suas práticas pedagógicas considerem as origens, condição cultural e a motivação de seus alunos, considerando que as necessidades educacionais, afetivas e cognitivas diferem-se, ou seja, cada aluno tem suas necessidades próprias e específicas. Findamos esse momento com um desejo de aprofundar na temática em estudos futuros, buscando compreender como os professores desenvolvem sua prática pedagógica com alunos indígenas com deficiências e como acontece o atendimento educacional especializado nas escolas das aldeias.

\section{REFERÊNCIAS}

ABE, Patrícia Bettiol. Desempenho funcional nas atividades de rotina escolar de alunos com necessidade educacionais especiais na perspectiva do. Marília, 2009. 100 f. Dissertação (Mestrado - Ensino na Educação Brasileira) - UNESP, Marília. 2009.

BRASIL, 2015. Lei Brasileira de Inclusão da Pessoa com Deficiência. Lei n. 13.146, de 6 de jul. de 2015 Disponível em: http://www.planalto.gov.br/ ccivil_03/_Ato2015-2018/2015/Lei/L13146.htm; acesso em: 24 nov. 2019. BUENO, José Geraldo Silveira. Crianças com necessidades educativas especiais, política educacional e a formação de professores: generalistas ou especialistas. Revista Brasileira de Educação Especial, v. 3, n. 5, p. 7-25, 1999.

CONNELY, F. M. e CLANDININ, D. J. Pesquisa Narrativa: experiência e história em pesquisa qualitativa. Uberlândia: EDUFU, 2011.

GALVÃO, C. Narrativas em Educação. Ciência \& Educação, Bauru, v. 11, n. 2, p. 327-345, 2005 Disponível em: <http://www.scielo.br/pdf/ciedu/ v11n2/12.pdf>, Acesso em: 10.06.2019. 
FREITAS, S. N. A formação de professores na educação inclusiva: construindo a base de todo o processo. In. RODRIGUES, D. Inclusão e educação: doze olhares sobre educação inclusiva. São Paulo: Summus, 2006.

FÁVERO, Osmar et al. (Org.) Tornar a educação inclusiva. Brasília: UNESCO, 2009.

MANTOAN, Maria Tereza. Eglér (org.) Inclusão Escolar: pontos e contrapontos. São Paulo: Summus, 2006.

OLIVEIRA, Ivone Martins de. A narrativa como possibilidade de abordagem dos conhecimentos produzidos pelo professor sobre sua prática. In: JESUS, Denise Meyrelles de et al. (Org.). Inclusão, práticas pedagógicas e trajetórias de pesquisa. Porto Alegre: Mediação/Prefeitura Municipal de Vitória/ CDV/FACITEC, 2007.

SOUZA, E. C. O conhecimento de si: Narrativas do itinerário escolar e formação de professores. Tese (Doutorado em Educação), Universidade Federal da Bahia, Faculdade de Educação, Bahia, Brasil, 2004. 